\title{
CONTRA A "VIOLÊNCIA DE INEXISTIR": PSICOLOGIA CRÍTICA E DIVERSIDADE HUMANA
} AGAINST THE "VIOLENCE OF THE INEXISTENCE": CRITICAL PSYCHOLOGY AND HUMAN DIVERSITY

\author{
Nuno Santos Carneiro \\ Universidade do Porto, Porto, Portugal
}

\section{RESUMO}

Ancorado numa perspectiva crítica, este artigo propõe uma revisão teórica sobre as abordagens psicológicas em torno da diversidade humana. Num primeiro momento, são examinadas as evoluções conceptuais que a noção de diversidade foi assumindo na psicologia. Posteriormente, elencamos algumas propostas epistemológicas consonantes com a perspectiva crítica adoptada. Por fim, procedemos a uma sistematização de princípios orientadores de uma praxis crítica celebrante da diversidade humana e combativa do que sugerimos ser a "violência de inexistir", representada pela rejeição das inumeráveis realidades subjectivas e relacionais que sempre nos caracterizam na diversidade.

Palavras-chave: diversidade humana; crítica; psicologia; epistemologias.

\begin{abstract}
Supported by a critical perspective, this article proposes a theoretical review on the psychological approaches to the human diversity. Firstly, we examine the conceptual evolutions that the notion of diversity has assumed in psychology. Then, we enlist some epistemological proposals consonant to the adopted critical perspective. Finally, we proceed with a systematisation of guiding principles of a critical praxis which both celebrates human diversity and fight against what we suggest as being the "violence of the inexistence", represented by the rejection of the uncountable subjective and relational realities which always characterises us within diversity.
\end{abstract}

Keywords: human diversity; critical; psychology; epistemologies.

\section{Pensar, dizer e fazer a diversidade}

Fenómenos persistentes como a xenofobia, as assimetrias de poder entre mulheres e homens, as profundas desigualdades económicas, a rejeição de orientações sexuais e de identidades de género diversas, entre tantos outros modos de violentar a existência, não deixam dúvidas sobre quão inseguras permanecem as sociedades para a expressão de múltiplas diversidades identitárias.

Não é fácil pensar ou escrever sobre diversidade humana. Por definição, a diversidade retrata tantas realidades quantas são aquelas que possamos vivenciar e percepcionar, mas retrata também as realidades que nos escapam à consciência e aos campos das nossas experiências subjectivas e relacionais. Ao mesmo tempo, não é raro que as ciências sociais se apoiem em pressupostos epistemológicos e ontológicos que desrespeitam a diversidade, quando legitimam processos que naturalizam as "diferenças" para manter o status quo e a ordem social (Baez, 2004).

Pensar sobre a diversidade resulta, assim, numa tarefa tão aliciante quanto complexa.

Neste artigo, propomos uma revisão teóricoconceptual e epistemológica a respeito da diversidade humana, abraçando uma leitura psicológica crítica - ou seja, uma leitura que compromete a psicologia com a rejeição activa das múltiplas facetas da discriminação social (e.g., Carneiro, 2009). O que se torna imperativo nesta psicologia crítica é a consciencialização das dificuldades "em lidar com as diferenças e com a existência do Outro de uma forma celebrativa em vez de opressiva" (Sampson, 2000, p.5).

Recorremos também a uma abordagem interdisciplinar consonante com os princípios fundadores da psicologia crítica (e.g., Fox, Prilleltensky 
\& Austin, 2009; Harris, 2009; Nogueira, 2001; Parker, 1999, 2007; Prilleltensky, 1997), começando por revistar caminhos históricos da abordagem psicológica do conceito de diversidade e considerando, posteriormente, algumas epistemologias consonantes com as reflexões adoptadas.

Tentando subsidiar a investigação psicológica sobre as temáticas da diversidade humana, conferimos um olhar actualizado a estas temáticas e ensaiamos, por fim, relacioná-las com uma praxis (também necessariamente crítica) potenciadora da integração de realidades subjectivas e sociais diversas.

Defendendo que é somente através destes modos críticos de pensar e de agir que a psicologia pode verdadeiramente entender que nos vamos fazendo humanamente na diversidade, este trabalho insurgese contra a "violência de inexistir", essa violência sempre representada pela recusa do valor inalienável da diversidade humana.

\section{Trajectórias conceptuais e epistemológicas a (des)respeito da diversidade}

\section{Da inferiorização e do défice à afirmação}

As primeiras abordagens psicológicas ao conceito de diversidade emergiram nos inícios do século passado tomando-o como sinónimo de inferiorização ou de menorização (Harris, 2009; Trickett, 2009; Trickett, Watts \& Birman, 1993, 1994; Watts, 1994). Na tentativa que era vigente de conferir à psicologia uma cientificidade regida pelo positivismo, esta menorização deu suporte ideológico a formas de exclusão e de eugenismo (de que fazem parte o etnocentrismo, o racismo ou o extermínio nazi) através da patologização da diversidade. A proliferação de estudos sobre a genética ou sobre as características inatas de personalidade atribuídas aos sujeitos que as "normas sociais" produziam como inferiores revela de forma inequívoca como a psicologia esteve ao serviço da patologização, para "explicar", "exilar", "curar" e "banir" estes sujeitos (e.g., Bayer, 1987; Carneiro, 2009; LeFevre, 2003; Moita, 2006; Richards, 1997; Sloan, 2009; Strickland, 2000).

Apenas as conturbações sociopolíticas iniciadas nos anos de 1960, orientadas para a constituição de movimentos sociais organizados que reivindicaram a dignificação de diferentes grupos sociais, puderam conduzir a mudanças de importante relevo para entender a diversidade. $\mathrm{O}$ mérito historicamente reconhecido a este período reside sobretudo nos esforços colectivos de mobilização de recursos e de condições contextuais que potenciassem o bem-estar das pessoas identificadas como pertencendo a categorias sociais de diversidade. De um registo conceptual anteriormente ancorado na inferiorização, a diversidade vai-se fundindo com a ideia de "défice" (Trickett, Watts, \& Birrman, 1993), ideia que traduz o desfavorecimento das posições social e psicologicamente experienciadas por quem não se enquadrava num registo "normativo" de expressão identitária. Contudo, a diversidade é ainda lida, neste paradigma de "défice", através de uma focalização nos aspectos debilitantes ou deficitários das diferenças identitárias, não promovendo portanto uma verdadeira integração do diverso.

$\mathrm{Na}$ década de 1980, as mudanças na conceptualização da diversidade irão tornar-se mais substantivas pela insatisfação que se vai desenvolvendo na psicologia face aos estereótipos negativos que as abordagens do "défice" lançaram sobre os "grupos minoritários". As psicologias culturalmente específicas (viz. empenhadas em conferir uma voz afirmada a diferentes grupos e identidades sociais) possibilitaram situar as questões da diversidade no tecido cultural e não, como anteriormente, nas diferenças individuais e grupais que esse mesmo tecido rotulava de "deficitárias" (cf. Watts, 1994). Passa então a enfatizar-se as identidades positivas partilhadas (e por isso afirmadas) pelos membros de grupos socialmente oprimidos, apelando assim a uma "diversidade afirmativa" (Trickett, 1994). Estão contempladas nesta noção de diversidade afirmativa as perspectivas psicológicas que olham para a diversidade não como retratando primariamente as "minorias" como grupos políticos de interesse mas, em vez disso, enfatizando que as experiências e as perspectivas dos diversos grupos contribuem para o enriquecimento do corpo social e, com isto, para a diversificação pluralizante do sujeito psicológico (e.g., Carneiro, 2009; Gato, Carneiro, \& Fontaine, 2011; Neves, 2007).

Trickett, Watts e Birman (1993) propõem, de acordo com esta abordagem afirmativa, que mais do que de diversidade falemos de "diversidade humana". Várias razões são apontadas para esta opção conceptual. Em primeiro lugar, com esta noção substituímos expressões como "minoria" ou "grupos de interesse", de forma a estabelecermos um olhar positivo sobre as diferenças individuais, mais do que colocarmos uma ênfase nas consequências negativas da opressão. Em sentido complementar, quando falamos de "humana" ampliamos a definição de diversidade para que nesta sejam incluídas as experiências de pessoas que são alvo de opressão em virtude de critérios múltiplos (orientação sexual, género, etnia, pobreza, incapacidade física ou psíquica...), não inferiorizando 
mas celebrando a riqueza contida nessas experiências. Por último, a expressão "diversidade humana" tem implicações ainda mais amplas, ao desconstruir a própria noção de "cultura maioritária" ou "dominante" fazendo esbater, deste modo, as fronteiras entre "minoria" e "maioria". O que assim se acusa é o facto de sermos habitualmente incapazes de questionar aprofundadamente o facto das culturas dominantes serem, também elas, marcadas pela complexidade que deriva da sua heterogeneidade.

Olhar para o mundo em que vamos acontecendo é olhar para as competências sociais e culturais, sempre específicas, sempre localizadas de todas as pessoas, cada vez mais diversas e diversificadas: "ao expandir o conceito de diversidade para incluir os membros da cultura dominante, a intenção é a de sublinhar as circunstâncias culturais e sociopolíticas particulares de todos os membros na nossa sociedade diversa" (Trickett, Watts, \& Birman, 1993, p. 265).

Veremos agora como este conceito de diversidade humana exige teorias de conhecimento congruentes com a sua definição crítica.

\section{Rumo a epistemologias críticas da diversidade humana}

Apenas através de uma mudança epistémica que se insurgiu contra as lógicas do positivismo foi possível que o conceito de diversidade incluísse identidades e contextos de pertença cada vez mais diferenciados, inclusive, como dissemos, pelo questionamento da ideia de culturas "dominantes" ou "maioritárias". É nessas lógicas positivistas que germinam e habitam as concepções de diversidade como "inferiorização" ou como "menorização" que anteriormente revimos. Guiada pelo essencialismo, a epistemologia positivista estabelece que as pessoas e os grupos sociais marcados como "inferiores" ou "menores" possuem características imutáveis e universais, porque independentes dos tempos e dos lugares em que se inscrevem. A "essência" serve para radicalizar a ideia de "ser", a ideia de que "se é" (e não de que "se vai sendo ou estando"), buscando caracterizações fixas, fixadas e fixantes desse "ser", através de esforços classificatórios contrários, como se percebe, à própria definição de diversidade humana (e.g., Bohan \& Russel, 1999; Fuchs, 2001).

Pelo contrário, as teorias do conhecimento que verdadeiramente celebram a multiplicidade de significados encetados na noção de diversidade humana estão obrigadas ao reconhecimento atento e sistemático de que as construções científicas jamais se desvinculam dos significados culturais e que jamais podem dissociar-se dos interesses e das posições ideológicas de quem produz essas construções (Baez, 2004; Bohan \& Russell, 1999; Nogueira, 2001).

De entre estas epistemologias críticas, é recorrentemente reconhecida uma particular contribuição do construcionismo social (cf. Nelson \& Prilleltensky, 2010), constituído como corrente teórica que se impõe contra o postulado da existência de uma verdade e de uma ontologia exteriores ao sujeito e, por consequência lógica, exteriores ao sujeito que produz conhecimento e que com ele inevitavelmente tem de comprometer-se (Berger \& Luckman, 1966; Burr, 1995; Gergen, 1999; Gergen \& Gergen, 2003). Nesta leitura, a noção de diversidade humana surge simultaneamente como produto e como produtora das posições pessoais, relacionais e culturais que ocupamos ou, pelo contrário, que somos impedidos de ocupar. As situações de opressão e as (im)possibilidades de acção para as combater pressupõem compreensões sempre contextualizadas, sempre imbuídas de padrões sociais que apenas ficticiamente distinguem o que é do que não é diverso.

Também a epistemologia ecológica, defensada como quadro de referência privilegiado para integrar a diversidade humana (Trickett, 2009; Trickett, Watts, \& Birman, 1993, 1994; Watts, 1994), dotou a psicologia de uma constante interrogação sobre "de que forma os valores sociais, reflectidos nas estruturas e nas políticas sociais, afectam diferencialmente a experiência de diversos grupos sociais" (Trickett, Watts, \& Birman, 1993, p. 273). Ao ter um ethos próprio, que é o das pessoas-em-comunidade, a ecologia remete obrigatoriamente para uma psicologia democrática, na medida em que todas as pessoas são ouvidas e participam na construção do conhecimento psicológico e para uma psicologia indígena, na medida em que são as pessoas e as comunidades quem melhor conhece as suas necessidades e quem melhor pode ajudar à construção de um saber que as respeite na sua diversidade.

Ainda assim, se a epistemologia social construcionista e a epistemologia ecológica têm sido reconhecidas como parte integrante e necessária de um paradigma crítico da diversidade humana, é também verdade que estas epistemologias são hoje encaradas como insuficientes para que este paradigma adquira uma representação efectiva e disseminada na psicologia (Fox, Prilleltensky, \& Austin, 2009; Kagan, Burton, Duckett, Lawthom, \& Siddiquee, 2011; Nelson \& Prilleltensky, 2010; Prilleltensky \& Nelson, 2002).

Como defendem Nelson e Prilleltensky (2010), os requisitos de um paradigma epistemológico crítico 
obrigam a que este paradigma: (a) seja orientado por uma agenda de empoderamento; (b) promova a adesão a valores das comunidades e a integração da diversidade humana nessas comunidades; (c) busque a justiça social e (d) tome a reflexividade como um valor central. Seguidamente, atenderemos às implicações destes requisitos.

Por promover o valor da auto-determinação, o empoderamento constitui um eixo central e estruturante da psicológica crítica (e.g., O’Donnell, 2006; Nelson \& Prilleltensky, 2010; Prilleltensky, 1997; Prilleltensky \& Nelson, 2002, 2009). Entendido enquanto conjunto de processos através dos quais os indivíduos e as suas comunidades vão ganhando poder ou mestria sobre os problemas que lhes são próprios (Rappaport, 1981), o empoderamento deve ser diferenciado, nos seus objectivos e nas suas estratégias, em função da diversidade que humanamente nos assiste. Na verdade, apenas no respeito e na celebração face a essa diversidade residem as bases para que tais estratégias e objectivos sejam efectivos (Trickett, 1994, 1996). Olhemos, ainda assim, para as várias críticas que o empoderamento tem merecido (e.g., Riger, 1993; Trickett, 1994). Desde logo, estas críticas radicam numa imprecisão conceptual que facilmente pode lesar o recurso ao empoderamento enquanto referencial teórico (Menezes, 2007). Adicionalmente, o individualismo e a responsabilização abusiva das pessoas e das comunidades frequentemente associados ao empoderamento (Prilleltensky, 1997; Prilleltensky \& Nelson, 2009; Riger, 1993; Trickett, 1994, 2009), põem em causa os princípios de autonomia enunciados por propostas que defendem a necessidade de empoderar as relações interpessoais em contextos de diversidade humana. Como diz Trickett (1994), o empoderamento continua, em muitas das suas formulações, a ser visto como qualidade psicológica ou como conjunto de qualidades psicológicas, o que conduz a uma diluição da ênfase política que deve dar-se àquele conceito. Esquece-se assim que são os factores situacionais, ideológicos, estruturais e políticos que ditam as possibilidades de poder ou da sua ausência, pelo que se as intervenções destinadas à promoção do empoderamento não levam em conta forças sociopolíticas mais amplas, é elevada a probabilidade de ficarem votadas a resultados infrutíferos. Por isso se afirma numa epistemologia crítica que sem atenção às dimensões políticas não há eficácia das modalidades de pensamento e de acção orientadas pelo empoderamento.

A última das críticas que é relevante revermos sobre este conceito prende-se com a tendência a defini-lo em moldes androcêntricos, já que os valores instrumentais (e definidores do empoderamento) de mestria, autonomia, poder ou controle na escolha e no envolvimento em contextos de relação humana são historicamente vistos como "masculinos" e não como "femininos". O reconhecimento da autonomia e da aquisição de poder sobre os problemas que nos afectam obriga a perceber que tais problemas "não são essencialmente derivados do género, mas das forças sociais mais amplas e das hierarquias sociais que se estabelecem em torno das preconcepções e das préatribuições de características de género" (Riger, 1993, p. 285).

No que toca à conciliação entre os pressupostos críticos da diversidade humana e a adesão aos valores das comunidades, o que se torna uma exigência é o envolvimento activo e efectivo de todas as pessoas dessas comunidades na interpretação dos processos e dos resultados dos projectos de intervenção, bem como o seu envolvimento em recomendações para a mudança. Deste modo, as pessoas terão de ser co-autoras dos projectos que a elas se dirigem e covinenciadoras das questões que as afectam.

Quanto à justiça social, o que de importante nos surge na lógica deste trabalho é sublinhar que ela depende, enquanto requisito crítico do pensamento na psicologia, da adequação dos saberes a cada comunidade e, com isto, a cada pessoa que nela possa dispor de uma distribuição igualitária de recursos pessoais, relacionais, físicos ou materiais para a sua emancipação a par da emancipação da(s) sua(s) comunidade(s) de pertença. Como afirmou Prilleltensky (1997), "a diversidade humana não pode florescer sem justiça e sem igualdade" (p. 522).

Vale ainda a pena tomar por referência Neves e Nogueira (2008), quando nos convidam a uma "inevitabilidade de se contestar a ordem dominante das ciências sociais, que para além de redutora, dado o seu carácter restritivo e não inclusivo, se tornou também opressora e limitadora das especificidades culturais e da diversidade societal" (p. 409). Combater esta tendência dominante das ciências sociais implica, também segundo as autoras, um constante exercício de reflexividade pessoal, enquanto "disciplina de auto-reflexão acerca de quem somos, de como as nossas identidades ... interferem no nosso trabalho e de como, por outro lado, o nosso trabalho influencia todos estes aspectos do nosso self" (p. 410). Sem esta reflexividade constante que a todos/as nos cabe quando situados numa epistemologia crítica, não será certamente possível que a diversidade humana se faça real.

Em suma, não tendo tentado proceder a uma exploração exaustiva das filosofias de conhecimento 
que têm possibilitado o desenvolvimento de abordagens críticas na psicologia a respeito da diversidade humana, até porque tal não caberia neste trabalho, o que pretendemos nesta revisão teórica foi apelar a epistemologias que apreciam o profundo valor da diversidade humana, pondo lado a lado a pluralização construtiva do corpo social e do sujeito psicológico (e.g., Baez, 2004; Frosh, 2000; Kovel, 1995; Parker, 2007). Contra as lógicas positivistas, as construções sociais, a ecologia e esforços integracionistas são fulcrais para respeitar a diversidade humana. Pelo empoderamento politicamente revestido, pela busca da justiça social, pela adesão aos valores das pessoas e das comunidades e pela saga da reflexividade, apenas as epistemologias críticas podem fazer jus à diversidade em que nos vamos fazendo. E apenas elas podem reger a conciliação entre o saber e o fazer que definem uma praxis favorecedora do que humanamente nos diversifica. Sobre esta praxis faremos alguns apontamentos.

\section{Apontamentos para uma Praxis Crítica: actuando na diversidade humana}

Davidson et al. (2006) referem que o pensamento crítico "tem focado mais os temas de desconstrução do que a construção ou a reconstrução ..., desafiando o status quo ao nível teórico mas muitas vezes falhando na extensão da teoria a uma acção orientada para a mudança social" (p. 45). A diversidade humana não se configura apenas como promessa de um "mundo novo" mas, mais do que isso, como um conjunto de realidades que inevitavelmente devem ligar essa promessa aos espaços da acção humana, levando-nos a ter que questionar que tipo de trabalho o trabalho da diversidade está fazendo actualmente e poderá fazer no futuro (Ahmed, 2007). Abordagens como estas reforçam a necessidade de articulação entre posições pensantes e actuantes que configurem uma praxis congruente com as trajectórias conceptuais e com as epistemologias da diversidade humana anteriormente consideradas.

Para esta praxis é crucial que os/as profissionais partilhem o poder, o que muitas vezes envolve um conflito entre o que é a sua visão e a visão das pessoas com quem trabalham. Trata-se de um conflito que é parte integrante e definidora de uma parceria com os sujeitos e com as comunidades a quem as intervenções psicológicas se destinam, numa oportunidade privilegiada, porque construtiva, para a aprendizagem e para reformulação de pressupostos e das visões sobre as experiências subjectivas e colectivas que são dadas, muitas vezes, como pré-garantidas. O desenvolvimento de processos de educação, de comunicação e de disseminação sistemática e reflexiva centrados nas intenções da intervenção e da forma como esta vai decorrendo (tanto nas suas evoluções, como nos seus impasses), dá corpo a uma praxis decorrente de valores, de teorias e de acções cujo objectivo maior é o da transformação das estruturas sociais no sentido da justiça social (Prilleltensky, 1997), em consonância com o que já antes afirmámos.

Pela tendência das ciências sociais de imposição totalizante ou hegemónica de saberes, o exercício de reflexividade que dissemos ter que ser desenvolvido pelos/as profissionais representa a vontade crítica de um "pensamento alternativo de alternativas" (Santos, 1999, p. 205). Pensar deste modo alternativo significa voltarmo-nos para a solidariedade e para a comunhão com as realidades da diversidade humana, de forma a desconstruirmos a ilusória cisão entre "Nós" e o "Outro".

O desafio que invariavelmente nos é colocado pela diversidade é paradigmático na psicologia ao iluminar que a vida humana tem tanto de psicológico quanto de social e de político (Trickett, Watts, \& Birman, 1993). Concordando com Menezes (2007), o que este desafio estabelece é um oficio do pluralismo, contrário a um oficio da verdade, na procura de confrontação de diferentes pontos de vista, tendo estes pontos de vista uma função inerentemente pluralizante: "o problema não é o de saber (ou descobrir) a verdade, mas de perceber a (inevitável) multiplicidade de pontos de vista sobre os problemas e as formas de os resolver" (p. 140).

A praxis crítica reveste-se, mais ainda, de um valor emocional e deve dirigir-se activamente para uma linguagem de compromisso. Como diz Ahmed (2007),

o compromisso torna-se uma forma de descrever o trabalho emocional da diversidade: as pessoas estão comprometidas com a diversidade no sentido em que ... realmente se preocupam sobre como adquirir a igualdade social e que expressam esta preocupação ou este cuidado pela forma como distribuem o seu tempo e a sua energia. (p. 249)

Faz então sentido dizer que uma praxis crítica da psicologia tem de recusar posições neutras em termos de valores, porquanto estas posições anulam a potencial celebração da diversidade humana. Só quando em compromisso ideológico com acções guiadas por valores que assumem e exigem a pluralização pode verdadeiramente falar-se numa praxis emancipatória (Prilleltensky, 1997; Prilleltensky \& Nelson, 2002, 2009). Enquanto valor-chave de uma esfera relacional do pensamento e da acção, a diversidade humana é o 
pano-de-fundo em que se tece o desenvolvimento de identidades pessoais e grupais positivas e em que se consolida o orgulho por essas identidades, requerendose para tal a criação de contextos de reconhecimento identitário que contrariam as normas e os valores mainstream.

Uma praxis crítica resulta, desta maneira, como mais transformativa do que melhorativa - ou seja, uma praxis que exige tanto um persistente trabalho de denúncia de todas as situações que calam a opressão ou a injustiça e que anulam (porque desrespeitam) a diversidade humana, quanto um contributo potencialmente reformulante destas condições. A acção crítica encaminha-se sempre para uma transformação profunda, que vai às causas das causas, podendo exigir, em função das necessidades, das histórias, das características e das especificidades identitárias, a criação de novos e/ ou mais adequados contextos de intervenção que comprometidamente favoreçam a emancipação humana. Só com esta intenção transformativa se pode revestir o paradigma crítico da intervenção com uma "validade psicopolítica" (Nelson \& Prilleltensky, 2010, p. 305). Esta noção integra, por um lado, a validade epistémica enquanto grau segundo o qual a investigação e a acção se comprometem com a distribuição do poder a diferentes níveis ecológicos (pessoal, relacional, organizacional...) e, por outro, a validade transformativa, entendida como o grau de transformação das estruturas sociais, através da libertação e da emancipação potenciáveis a partir destas estruturas.

Assumimos, por último, a importância que na praxis crítica assumem os esforços de "descolonização do espaço psíquico", entendidos como esforços que permitem que "os alvos da diminuição cultural resistam às prescrições negativas que lhes são atribuídas pela cultura dominante" (Prilleltensky \& Nelson, 2009, p. 139). Tendo por base esta descolonização psíquica, torna-se possível que a psicologia crítica solidifique as intenções que lhe são inerentes de respeito pela "natureza policêntrica da mente" (Kovel, 1995) ou, dizendo de outro modo, trabalhando para colocar lado a lado a abertura das comunidades, do corpo social e das realidades psicológicas e experienciais à existência do "Outro".

\section{Contra a "violência de inexistir"}

$\mathrm{O}$ (re)conhecimento das evoluções conceptuais e epistemológicas em torno da diversidade humana, de que este artigo se ocupou, é em si mesmo um processo que permite ilustrar de modo exemplar como (também) através da psicologia se foram marcando "diferenças" no espaço do humano, num caminho histórico e de construção de conhecimento que tem violentado a existência do diverso. Que o tem violentado pela inferiorização, pela desigualdade "deficitária" face ao que erradamente se entende como não-diverso ou pelas tentativas de incorporação dominada e dominante da "diferença" no corpo social que apenas de jeito ilusório se impõe como "maioritário".

Até que seja possível integrar a diversidade humana, e até que ela se faça enriquecedora da psicologia, das ciências sociais e do plano político, a violência impera como impedimento sobre todos/as nós de nos vermos celebrados/as na diversidade que é a nossa, ao sê-lo sempre de forma reflexiva, localizada, psíquica e culturalmente descolonizada, diferenciada e legitimada. Porque "na perspectiva da diversidade humana, toda a gente tem uma cultura, uma raça, um género, uma orientação sexual e um lugar na ordem social" (Trickett, Watts, \& Birman, 1993, p. 265).

Como se disse, uma praxis crítica exige que os/ as profissionais desenvolvam uma sensibilidade ao "Outro", que progressivamente façam deste "Outro" um "Nós", numa lógica afirmativa da intervenção que se quer conhecedora de experiências multiformes e multiculturais (e.g., Carneiro, 2009; Carneiro \& Menezes, 2006, 2007; Moleiro \& Pinto, 2009; Neves, 2007). O respeito pela diversidade humana nas intenções de pensamento e de acção da psicologia crítica gera novas e reformuladas identidades profissionais, alimentadas pelo desafio construtivo de perspectivas.

O que neste artigo quisemos também deixar claro foi a necessidade de pensar e de agir contra a violência de não reconhecer quem está remetido para a exclusão. Mas igualmente de pensar e de agir contra a violência de não nos reconhecermos em nós como mais plurais na diversidade humana, o que implica a aprendizagem e a afirmação de novos olhares a propósito do "normativo", do "maioritário" ou do "dominante". Não o fazermos é votarmo-nos a um reducionismo, sempre contrário à possibilidade de construirmos um mundo (mais) crítico.

Reclamamos, enfim, uma psicologia que é de todos/as e para todos/as e apenas capaz de sobreviver se situada na diversidade humana. Porque "o único modo de lidar com a contemporaneidade é, precisamente, não se recusar a vivê-la" (Louro, 2008, p. 23), no que ela tem de tão rico e desafiante: a diversidade humana trazida, sem pedidos subjugados, ao esplendor que melhor a define.

Porque irmos sendo no humano não é senão irmos sendo na diversidade. 


\section{Agradecimento}

Este trabalho foi produzido com o apoio de uma Bolsa de Pós-Doutoramento da FCT - Fundação para a Ciência e a Tecnologia (referência de bolsa: SFRH / $\mathrm{BPD} / 68661$ / 2010).

\section{Referências}

Ahmed, S. (2007). The language of diversity. Ethnic and Racial Studies, 30(2), 235-256.

Baez, B. (2004). The study of diversity: The "knowledge of difference" and the limits of science. The Journal of Higher Education, 75(3), 285-306.

Bayer, R. (1987). Homosexuality and American psychiatry: The politics of diagnosis. New Jersey, NJ: Princeton University Press.

Berger, P. L. \& Luckman, T. (1966). The social construction of reality: A treatise in the sociology of knowledge. New York, NY: Anchor Books.

Bohan, J. S. \& Russel, G. M. (1999). Conversations about psychology and sexual orientation. New York, NY: New York University Press.

Burr, V. (1995). Social constructionsim. New York, NY: Routledge.

Carneiro, N. S. (2009). "Homossexualidades": Uma psicologia entre ser, pertencer e participar. Porto: LivPsic.

Carneiro, N. S. \& Menezes, I. (2006). "Do anel à aliança": Sentido dos iguais e emancipação social na psicologia das sexualidades. Revista Crítica de Ciências Sociais, 76, 73-89.

Carneiro, N. S. \& Menezes, I. (2007). From an oppressed citizenship to affirmative identities: Lesbian and gay political participation in Portugal. Journal of Homosexuality, 53(3), $65-82$.

Davidson, H., Evans, S., Ganote, C., Henrickson, J., JacobsPriebe, L., Jones, D. L., Prilleltensky, I., \& Riemer, M. (2006). Power and action in critical theory across disciplines: Implications for critical community psychology. American Journal of Community Psychology, 38, 35-49.

Fox, D., Prilleltensky, I., \& Austin, S. (2009). Critical psychology for social justice: Concerns and dilemmas. In D. Fox, I. Prilleltensky, \& S. Austin (Eds.), Critical psychology: An introduction (pp. 3-19). London: Sage.

Frosh, S. (2000). In praise on unclean things: Critical psychology, diversity and disruption. In T. Sloan (Ed.), Critical psychology: Voices for change (pp. 55-66). London: Macmillan.

Fuchs, S. (2001). Against essentialism: A theory of culture and society. Cambridge: Harvard University Press.

Gato, J., Carneiro, N. S., \& Fontaine, A. M. (2011). Contributo para uma revisitação histórica e crítica do preconceito contra as pessoas não heterossexuais. Critica e Sociedade: Revista de Cultura Política, 1(1), 139-167.

Gergen, K. J. (1999). An invitation to social construction. London: Sage.

Gergen, K. J. \& Gergen, M. (Eds.). (2003). Social construction: $A$ reader. Thousand Oaks, CA: Sage.

Harris, B. (2009). What critical psychologists should know about the history of psychology. In D. Fox, I. Prilleltensky, \& S. Austin (Eds.), Critical psychology: An introduction (pp. 20-35). London: Sage.
Kagan, C., Burton, M., Duckett, P., Lawthom, R., \& Siddiquee, A. (2011). Critical community psychology: Critical action and social change. London: Wiley-Blackwell.

Kovel, J. (1995). On racism and psychoanalysis. In A. Elliot \& S. Frosh (Eds.), Psychoanalysis in contexts: Paths between theory and modern culture (pp. 205-222). London: Routledge.

LeFevre, J. (2003). The value of diversity: A justification of affirmative action. Journal of Social Philosophy, 34(1), 125-133.

Louro, G. L. (2008). Género e sexualidade: Pedagogias contemporâneas. Pro-Posições, 19, 2(56), 17-23.

Moita, G. (2006). A patologização da diversidade sexual: Homofobia no discurso de clínicos. Revista Crítica de Ciências Sociais, 76, 53-72.

Menezes, I. (2007). Intervenção comunitária: Uma perspectiva psicológica. Porto: LivPsic e Legis Editora.

Moleiro, C. \& Pinto, N. (2009). Diversidade e psicoterapia: Expectativas e experiências de pessoas LGBT acerca das competências multiculturais de psicoterapeutas. Ex-Aequo, 20, 159-172.

Nelson, G. \& Prilleltensky, I. (2010). Community psychology: In pursuit of liberation and well-being ( $2^{\mathrm{a}}$ ed.). New York, NY: Palgrave Macmillan.

Neves, S.(2007).Psicologia, diversidadesocialemulticulturalidade: caminhos cruzados. Psychologica, 45, 125-145.

Neves, S. \& Nogueira, C. (2008). Metodologias feministas: a reflexividade ao serviço da investigação nas ciências sociais. Psicologia: Reflexão e Crítica, 18(3), 408-412.

Nogueira, C. (2001) Um novo olhar sobre as relações sociais de género: Feminismo e perspectivas críticas na psicologia social. Lisboa: Fundação Calouste Gulbenkian e Fundação para a Ciência e a Tecnologia.

O'Donnell, C. R. (2006). Beyond diversity: Toward a cultural community psychology. American Journal of Community Psychology, 37(1-2), 1-7.

Parker, I. (1999). Critical psychology: Critical links. Annual Review of Critical Psychology, 1, 3-18.

Parker, I. (2007). Revolution in psychology: From alienation to emancipation. London: Pluto Press.

Prilleltensky, I. (1997). Values, assumptions, and practices: Assessing the moral implications of psychological discourse and action. American Psychologist, 52(5), 517-535.

Prilleltensky, I. \& Nelson, G. (2002). Doing psychology critically: Making a difference in diverse settings. New York, NY: Palgrave McMillan.

Prilleltensky, I., \& Nelson, G. (2009). Community psychology: Advancing social justice. In D. Fox, I. Prilleltensky, \& S. Austin (Eds.), Critical psychology: An introduction (pp. 126-143). London: Sage.

Rappaport, J. (1981). In praise of paradox: A social policy of empowerment over prevention. American Journal of Community Psychology, 9, 1-25.

Richards, G. (1997). “Race”, racism and psychology: Towards a reflexive history. London: Routledge.

Riger, S. (1993). What's wrong with empowerment. American Journal of Community Psychology, 21(3), 279-292.

Sampson, E. (2000). On rainbows and differences. In T. Sloan (Ed.), Critical psychology: Voices for change (pp. 1-5). London: Macmillan.

Santos, B. S. (1999). Porque é tão difícil construir uma teoria crítica? Revista Crítica de Ciências Sociais, 54, 197-215.

Sloan, T. (2009). Theories of personality. In D. Fox, I. Prilleltensky, \& S. Austin (Eds.), Critical psychology: An 
introduction (pp. 57-74). London: Sage.

Strickland, B. R. (2000). Misassumptions, misadventures, and the misuse of psychology. American Psychologist, 55(3), 331-338.

Trickett, E. J. (1994). Human diversity and community psychology: Where ecology and empowerment meet. American Journal of Community Psychology, 22(4), 583-592.

Trickett, E. J. (1996). A future for community psychology: The contexts of diversity and the diversity of contexts. American Journal of Community Psychology, 24(2), 209-234.

Trickett, E. J. (2009). Community psychology: Individuals and interventions in community context. Annual Review of Psychology, 60, 395-419.

Trickett, E. J., Watts, R. J., \& Birman, D. (1993). Human diversity and community psychology: Still hazy after all these years. Journal of Community Psychology, 21, 264-279.

Trickett, E. J., Watts, R. J., \& Birman, D. (1994). Toward an overarching framework for diversity. In E. J. Trickett, R. J. Watts, \& D. Birman (Eds.), Human diversity: Perspectives on people in context (pp. 7-26). San Francisco, CA: JosseyBass Publishers.

Watts, R. J. (1994). Paradigms of diversity. In E. J. Trickett, R. J. Watts, \& D. Birman (Eds.), Human diversity: Perspectives on people in context (pp. 49-80). San Francisco, CA: JosseyBass Publishers.

Recebido em: 07/11/2011

Revisão em: 07/04/2012

Aceite em: 09/04/2012

Nuno Santos Carneiro é Doutor em Psicologia e Membro Integrado do Centro de Psicologia da Universidade do Porto - Faculdade de Psicologia e de Ciências da Educação. Endereço: Rua Alfredo Allen. Porto, Portugal. 4200-135. Email: nunoscarneiro@gmail.com

\section{Como citar:}

Carneiro, N. S. (2013). Contra a "violência de inexistir": psicologia crítica e diversidade humana. Psicologia \& Sociedade, 25(1), 40-47. 